Original article

\title{
Newcastle disease virus (NDV) modulates pro/antioxidant status in different brain regions of chicken
}

\author{
Kadiam C. Venkata Subbaiah ${ }^{a}$, Rajendra Wudayagiri ${ }^{b}$, Lokanatha Valluru ${ }^{\mathrm{a}, *}$ \\ a Department of Biotechnology, Dravidian University, Kuppam, A.P 517 426, India \\ ${ }^{\mathrm{b}}$ Department of Zoology, Sri Venkateswara University, Tirupati, A.P 517 502, India
}

\section{A R T I C L E I N F O}

Article history:

Received 18 March 2013

Accepted 23 May 2013

Available online 20 August 2013

\section{Keywords:}

Newcastle disease virus

Brain regions

Oxidative stress

Antioxidant metabolism

Chicken

\begin{abstract}
A B S T R A C T
Background: Newcastle disease (ND) is highly contagious disease caused by Newcastle disease virus (NDV) causes mass mortalities in poultry and triggers poultry economy.

Methods: NDV induced oxidative stress representing marker enzymes and lipid peroxidation levels were evaluated in tissues of control and virus infected animals by using standard protocols and methods. Results: Lipid peroxidation levels were significantly increased in cerebrum and cerebellum of NDV infected chickens on 10 (dpi) as compared to controls. The activities of superoxide dismutase, catalase and glutathione metabolism representing enzymes were significantly decreased in cerebrum and cerebellum. Extensive histopathological malformations were observed in cerebrum and cerebellum.

Conclusion: The results of the present study, thus demonstrated that region specific alterations in the antioxidant defense mechanism due to NDV infection suggesting its critical role in cellular injury prominently in cerebrum and cerebellum and moderately in optic lobes of brain. The findings could help to advance the therapeutic armamentarium for control of Newcastle disease in poultry.

Copyright $\odot$ 2013, SciBiolMed.Org and Phcog.Net, Published by Reed Elsevier India Pvt. Ltd. All rights reserved.
\end{abstract}

\section{Introduction}

Newcastle disease (ND) is one of the economically-important poultry diseases all over the world. ND is caused by virus of the genus avulavirus belonging to the family paramixoviridae., ${ }^{1,2}$ The structural organization of ND virus (NDV) consists of a single stranded negative-sense RNA as a genetic material with a molecular weight of $5.2-5.6 \times 10^{6} \mathrm{Da}$ and associated with six proteins.

The structurally associated proteins such as nucleoprotein, phosphoprotein and the large polymerase protein form the nucleocapsid, the hemagglutinin-neuraminidase and fusion proteins constitute the external envelope, and the matrix protein forms the inner layer of the virion. ${ }^{2}$ Earlier, it has been suggested that NDV induced pathogenicity is mainly due to the presence of multiple basic amino acids at the cleavage site of fusion protein and also the presence of amino acid phenylalanine at position $117 .^{3}$ It has also been suggested that the severity of ND affects almost all vital organs and leads to respiratory failure, gastrointestinal problems, reproductive dysfunction, neuronal disorders and hemorrhagic lesions and eventually causes death of chickens. Due to potentially

\footnotetext{
* Corresponding author. Tel.: +919652840923 (mobile).

E-mail address: lokanathav@yahoo.co.in (L. Valluru).
}

high mortality rates, NDV infections are recognized as a significant health risk to the poultry-farming. ${ }^{4}$ Though, many studies indicated the chemical nature and target organs of NDV, studies pertaining to the mode of action of NDV are little understood.

It is well established that homeostasis of pro- and anti-oxidant balance is crucial for organisms structural and functional integrity. In general, under normal physiological conditions, excessive generation of free radicals is neutralized by intrinsic antioxidant defense system. ${ }^{5,6}$ Thus, alterations at the level of pro- and antioxidant axis might adversely target physiological functions of an organism. Previously, it has been suggested that virus-induced pathogenicity at least in part mediates oxidative stress ${ }^{7}$ thereby affects target organs. Further, it has also been claimed that reactive oxygen species (ROS) and nitrogen species (RNS) play an important role in many viral infections and disease pathogenesis and/or progression. ${ }^{8,9}$ It has been reported that, ROS and RNS at low levels play a key role in the host defense system through bactericidal and/ or virucidal action on invading microorganisms, whereas at high levels, they amend the progressiveness of cells to viral replication, regulate host inflammatory and immune system, which subsequently causes oxidative damage to both host tissue and progeny virus. $^{10}$ Several in vitro studies indicated that viruses have been found to induce excessive ROS and RNS in tissue culture systems. ${ }^{11}$ On the other hand, many in vivo studies also suggested that 
oxidative stress caused by influenza and paramyxoviruses, ${ }^{12}$ hepatitis B virus and HIV ${ }^{13}$ mediates a dramatic increase in the levels of ROS. Further, it has also been reported that alpha-herpesvirusmediated oxidative stress leads to Marek's disease in chickens. ${ }^{14}$ Recently, findings from our laboratory also suggested that, NDV induces oxidative stress in almost all vital parts of the chicken including brain. ${ }^{15}$ Thus, though unclear, it seems apparent that oxidative stress is one of the mechanisms of viral pathogenesis.

Brain is one of the important target organs of viral infections including NDV. Many studies also indicated that oxidative damage due to increased ROS and RNS is an emerging mechanism of viralinduced nervous system injury. ${ }^{16}$ Earlier, it has been reported that experimental infection with NDV in day old male layer chicken showed alterations in the glutamate metabolism and cholinergic neuronal transmission in different brain regions. ${ }^{17,18}$ Therefore, it is clear that NDV infection affects all compartments of brain, however, information related to the generation of NDV induced ROS and RNS in different brain regions is yet to be resolved. Thus, the present study was aimed to address the gaps related to the NDV induced alterations in pro- and anti-oxidant status in different parts of brain regions in chickens.

\section{Materials and methods}

\subsection{Chemicals}

Iodonitrotetrazolium chloride, Epinephrine, Bovine Serum Albumin, NADPH, GSSG, NAD and GSH were purchased from Sigma Chemical Company, St Louis, MO, USA. All other chemicals used were of analytical grade and obtained from local commercial sources.

\subsection{Experimental animals and maintenance}

In the present study day old, male chicken (Gallus domesticus; BV 300 ) with body weights ( $35 \pm 5 \mathrm{~g}$ ) was selected as experimental animals. The specific pathogenic free chicken was purchased from Balaji Hatcheries Pvt. Ltd., Chittoor, A.P. Animals were maintained in separate isolators with ad libitum access to feed and water in an air-conditioned environment $\left(35 \pm 2{ }^{\circ} \mathrm{C}\right)$ with a 12-h light and 12 -h dark cycle. The experiments were carried out in accordance with the guidelines of the Committee for the Purpose of Control and Supervision on Experiments on Animals, Government of India (CPCSEA, 2003). The experiments were also reviewed and approved by the Animal Ethical Committee at Sri Venkateswara University, Tirupati, India (vide no. 04/a/CPCSEA/IAEC/08-09/ZOOL/WR/dated 01.09.2009).

\subsection{Virus}

Ranikhet disease virus K (Kumarov mesogenic reference strain, India) was obtained from Sri Venkateswara Veterinary University, Tirupati, A.P, India. The stock of NDV was maintained on embryonated egg passages and the titer of NDV stock is 1024 HA units and it was stored at $-40{ }^{\circ} \mathrm{C}$ until use.

\subsection{Animal infection and treatment}

100-200 $\mu \mathrm{l}$ of NDV ( ID $_{50} 10^{9.4}$ units/ml) was injected into each animal by intra-muscular route (IM) for induction of Newcastle disease. ${ }^{15}$ All animals were monitored for disease symptoms and the characteristic clinical signs (i.e. nasal discharges, watery diarrhea, twisted neck and paralyzed legs) were observed during experimental period. Chicken in group I $(n=6)$ received $200 \mu \mathrm{l}$ of phosphate buffered saline and served as controls, chicken in group
II (4 days) and group III (10 days) received intra-muscular injections with 100-200 $\mu \mathrm{l}$ of NDV. All the birds were sacrificed on 4th and 10th day. In our preliminary studies, lethargic symptoms were observed on day 4 and $>90 \%$ mortality was observed on day 11 . Thus, for the present study, treatment duration 4 and 10 days were selected.

\subsection{Hemagglutination inhibition test}

For conformation of ND disease, chicken was tested for HI-titer; Animals were restrained manually and $200 \mu \mathrm{l}$ of blood sample was collected from cervical vein using a $0.5 \mathrm{ml}$ syringe, then placed in micro tube with EDTA and immediately transferred to laboratory. ${ }^{19}$ Newcastle disease (ND) HI-titer was determined by a procedure in the following; a two fold serial dilution of serum was made in a 96 well, $\mathrm{V}$-shaped bottom microtitre plate containing $25 \mu \mathrm{l}$ of buffer of $\mathrm{pH} 7.2-7.4$ and $25 \mu \mathrm{l}$ of serum in all wells. Twenty-five microtitres of ND virus antigen was added to all the wells except for the last row (controls). Serum dilutions ranged from 1:2 to $1: 2048$. The antigen serum mixture was incubated for $10 \mathrm{~min}$ at 37 . Fifty micro liters of a $0.5 \%$ erythrocyte suspension was added to each well and the wells repeatedly incubated for $30 \mathrm{~min}$. A positive serum, a negative serum, erythrocytes and antigens were also included as controls. The highest dilution of serum causing complete inhibition of erythrocyte agglutination was considered as the end point. The geometric mean titer was expressed as the reciprocal $\log 2$ values of the highest dilution that displayed anti ND-HI.

\subsection{Histopathological examination}

At the time of euthanize, different brain regions were isolated and immediately fixed in $10 \%$ formalin. Samples were routinely processed in gradient concentrations of alcohol and water and embedded in paraffin. Paraffin blocks were cut using a rotational microtome; Sections of $5 \mu \mathrm{m}$ were stained with hematoxylin and eosin (H\&E) and histopathological changes were observed under the light microscope.

\subsection{Preparation of tissue homogenates}

Chicken was terminated by cervical dislocation and brain of infected and control animals were isolated. Brain regions (cerebrum, cerebellum, optic lobes and brain stem) were dissected and homogenized in chilled $0.1 \mathrm{M}$ phosphate buffered saline $(10 \% \mathrm{w} / \mathrm{v})$ using a glass homogenizer with a Teflon pestle.

\subsection{Assay of antioxidants and antioxidant enzymes}

Selected biochemical constituents and enzymes representing antioxidant metabolism were estimated in selected tissues of control and experimental chicken. MDA levels were estimated according the method of. ${ }^{20}$ Reduced glutathione was estimated by the method of. ${ }^{21}$ The activity of superoxide dismutase (Mn-SOD) was assayed by the method of. ${ }^{22}$ The activity levels of glutathione peroxidase (GPx), catalase (CAT), glutathione-S-transferase (GST) and glutathione reductase (GR) were assayed by the methods of Refs. $^{13,23-25}$ respectively. Protein content was determined following the method of ${ }^{26}$ using bovine serum albumin as a reference standard.

\subsection{Statistical analysis}

The data were statistically analyzed using one way analysis of variance (ANOVA) followed by Tukey's multiple comparison test using Student Version 16.0, SPSS Inc., Chertsey, UK. The data were 
presented as mean \pm S.D $(n=6)$. Differences were considered to be significant at $p<0.001,0.05$ and 0.01 .

\section{Results}

Chickens were observed for Newcastle disease clinical signs and symptoms during experimental period. Significant behavioral changes like twisted neck, paralyzed legs, greenish diarrhea and ruffled feathers were noted. On the other hand, a significant increase in the haemagglutination titers as compared to second day of infection (Fig.2) and the titer of HI (1.38 \pm 0.01$)$. Further, significant decrease in the body weights of birds as compared to healthy birds (data not shown).

A significant decrease in the levels of reduced glutathione content and the activities of Mn-SOD, CAT, GPx, GR and GST in the cerebrum cerebellum and optic lobes of NDV infected chicken when compared to controls (Tables 1-3). Besides, a significant increase was observed in the MDA levels in cerebrum, cerebellum and optic lobes as compared to their respective controls. Whereas in brain stem (Table 4), slight changes (not significantly) in antioxidant defense system was also observed during experimental infection period.

Extensive histopathological malformations were recorded in cerebrum, cerebellum and optic lobes of NDV infected chicken after 10 days post infection period (dpi) (Fig. 1). Increased glial cell population, hemorrhage, encephalomalacia, perivascular monocyte aggregations, vacuolated cytoplasm and lymph mononuclear infiltration were observed in cerebrum and cerebellum of NDV infected chicken (Fig.1IA, IIA, IIIA).

\section{Discussion}

Brain is a fundamental vital organ, which plays a crucial role in signaling circuits of animals. It is also well established that a balance between pro- and anti-oxidant defense systems is critical in the regulation of physiological functions of vital organs including brain. ${ }^{27}$ Thus any alterations in the pro- and anti-oxidant status have great impact on the brain functions. It is believed that, brain has a high concentration of polyunsaturated fatty acids (PFUA),
HA titer

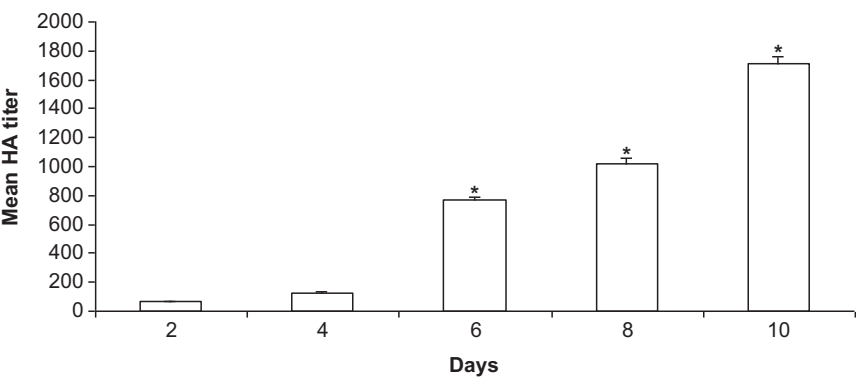

Fig. 2. Mean of hemagglutination titers after the inoculation of chickens with Newcastle disease virus. *Indicates significantly different from 2-day experimental period $(p<0.05)$.

high oxygen content and progressive accumulation of iron content compared to any other tissues of the body therefore, brain is highly susceptible target to oxidative damage while during in neuro pathophysiological conditions. ${ }^{15,28}$ In the present study, there was a significant increase in the lipid peroxidation levels in cerebrum, cerebellum and optic lobes of chicken exposed to NDV. Many reports claim that quantification of malondialdehyde levels has been used as an indicator of oxidative stress. ${ }^{29}$ The increase in the lipid peroxidation content accompanied by a significant decrease in the activity levels of SOD, CAT and glutathione related enzymes in the cerebrum, cerebellum and optic lobes regions suggest that NDV has ability to induce region specific oxidative stress, prominently in cerebrum and cerebellum $(p<0.001)$ and moderately $(p<0.05)$ in optic lobes of brain. Our findings are in good accordance with the studies of, ${ }^{27}$ they have suggested that, region specific oxidative stress occurred during Japanese encephalitis virus infection in animal model and leading to tissue injury. It is well acknowledged that an intrinsic antioxidant mechanism is involved to protect the cells from ROS-induced damage or to check their levels within normal limits. Under physiological conditions, SOD is believed to be the first line of antioxidant enzyme which converts ROS, the superoxide anion, into hydrogen peroxide and molecular oxygen and
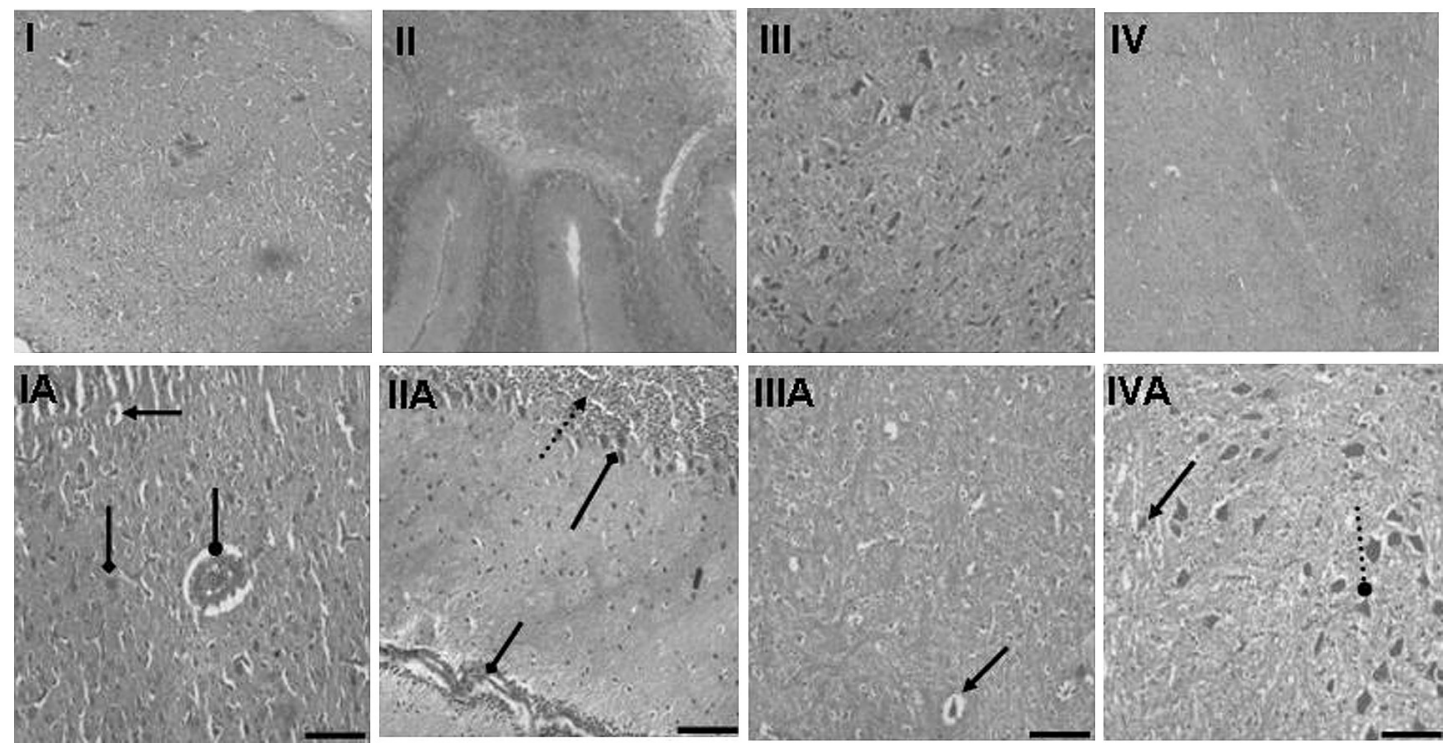

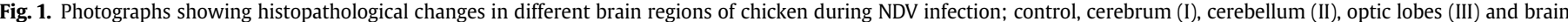

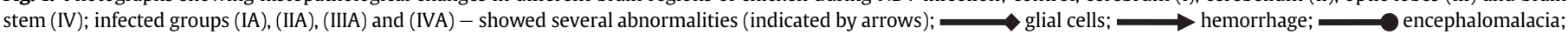
..... lymph mononuclear infiltrate; .... v vacuolated cytoplasm. H\&E stain: Lens $(\times 40$ IA-IVA \& $\times 10$ I-IV). Bars $=10 \mu \mathrm{m}$. 
Table 1

Effect of Newcastle disease virus infection on the levels of antioxidant and the activities of antioxidant enzymes in the cerebrum of chicken.

\begin{tabular}{lcrr}
\hline Parameter & Control & \multicolumn{2}{l}{ NDV infection } \\
\cline { 3 - 4 } & \multicolumn{2}{c}{4 Days } & \multicolumn{1}{c}{10 Days } \\
\hline Superoxide dismutase $^{\mathrm{a}}$ & $3.50 \pm 0.125$ & $3.76 \pm 0.071^{\mathrm{ns}}$ & $2.15 \pm 0.119^{\Psi}$ \\
Catalase $^{\mathrm{a}}$ & $2.10 \pm 0.196$ & $2.31 \pm 0.122^{\mathrm{ns}}$ & $1.10 \pm 0.165^{\Psi}$ \\
Glutathione-S-transferase $^{\mathrm{b}}$ & $299.05 \pm 9.132$ & $301.08 \pm 9.33^{\mathrm{ns}}$ & $220.24 \pm 12.39^{\Psi}$ \\
Glutathione peroxidase $^{\mathrm{c}}$ & $30.53 \pm 1.25$ & $31.33 \pm 0.98^{\mathrm{ns}}$ & $20.86 \pm 1.52^{\Psi}$ \\
Glutathione reductase $^{\mathrm{d}}$ & $13.99 \pm 0.349$ & $13.92 \pm 0.829^{\mathrm{ns}}$ & $7.95 \pm 0.8^{\Psi}$ \\
Reduced glutathione $^{\mathrm{e}}$ & $41.04 \pm 2.51$ & $43.2 \pm 2.81^{\mathrm{ns}}$ & $29.608 \pm 1.9^{\Psi}$ \\
Lipid peroxidation $^{\mathrm{f}}$ & $56.71 \pm 1.67$ & $64.20 \pm 2.01$ & $89.02 \pm 2.33^{\Psi}$
\end{tabular}

Values are expressed as mean \pm S.D of six individual observations. ${ }^{\Psi} p<0.001$ between control group and 10 days NDV infected group. ns = Non significant.

a Expressed in $\mathrm{U} / \mathrm{mg}$ of protein.

b Nano mol of CDNB conjugate formed/mg of protein $/ \mathrm{min}$.

c Milli units/mg of protein.

d nmol of NADPH oxidized/min/mg of protein.

e $\mathrm{nM} / \mathrm{mg}$ of protein.

f $\mu$ moles of MDA formed/gm wet weight of tissue/h.

the resulting hydrogen peroxide is converted to water by CAT and GPx and thereby protects the cells from hydrogen peroxide and hydroxyl radicals. ${ }^{6}$ In the present study, the activities of SOD and CAT were significantly lowered in cerebrum, cerebellum and optic lobes, due to an over accumulation of superoxide radicals and hydrogen peroxide radicals. It was reported earlier that superoxide radicals and hydro peroxide anions stringently inhibit the catalase and superoxide dismutase activities in virus infected animals. ${ }^{30,31}$ However, the exact mechanism by which they inhibit the enzyme activities is not known. Thus the decrease in catalase and SOD concentrations could be due to the direct attack by free radicals that are generated during respiratory burst, activated by macrophages. 8,31 Our results were corroborated with the findings of Sugino et al., $1988^{32}$ also reported decreased SOD activity levels in mice infected with influenza virus.

Glutathione metabolism occupies a strategic position in the antioxidant status and also in detoxification system. Thus, regulation of glutathione metabolism is pivotal for cellular defense against oxidative injury and for cellular integrity ${ }^{33}$ which in turn reflects detoxification mechanisms. Glutathione peroxidase (GPx) plays an important role in the detoxification of hydrogen peroxides, with the conversion of reduced glutathione (GSH) to glutathione disulfide GSSG. ${ }^{34}$ In the present study, the decreased activity levels of GPx in cerebrum, cerebellum and optic lobes of NDV infected

Table 2

Effect of Newcastle disease virus infection on the levels of antioxidant and the activities of antioxidant enzymes in the cerebellum of chicken.

\begin{tabular}{lccc}
\hline Parameter & Control & \multicolumn{2}{l}{ NDV infection } \\
\cline { 3 - 4 } & & 4 Days & \multicolumn{1}{c}{10 Days } \\
\hline Superoxide dismutase $^{\mathrm{a}}$ & $2.84 \pm 0.22$ & $2.96 \pm 0.196^{\mathrm{ns}}$ & $1.66 \pm 0.077^{\Psi}$ \\
Catalase $^{\mathrm{a}}$ & $2.53 \pm 0.08$ & $2.67 \pm 0.14^{\mathrm{ns}}$ & $1.22 \pm 0.15^{*}$ \\
Glutathione-S-transferase $^{\mathrm{b}}$ & $259.61 \pm 9.2$ & $262.19 \pm 9.9^{\mathrm{ns}}$ & $210.05 \pm 9.19^{\Psi}$ \\
Glutathione peroxidase $^{\mathrm{c}}$ & $29.56 \pm 1.92$ & $30.61 \pm 1.56^{\mathrm{ns}}$ & $21.15 \pm 1.04^{\Psi}$ \\
Glutathione reductase $^{\mathrm{d}}$ & $12.52 \pm 0.75$ & $13.17 \pm 0.63^{\mathrm{ns}}$ & $6.98 \pm 0.42^{\Psi}$ \\
Reduced glutathione $^{\mathrm{e}}$ & $38.89 \pm 1.83$ & $40.23 \pm 2.1^{\mathrm{ns}}$ & $25.51 \pm 1.01^{*}$ \\
Lipid peroxidation $^{\mathrm{f}}$ & $52.03 \pm 2.01$ & $58.64 \pm 1.54$ & $74.52 \pm 2.25^{\Psi}$ \\
\hline
\end{tabular}

Values are expressed as mean \pm S.D of six individual observations. ${ }^{\Psi} p<0.001$ between control group and 10 days NDV infected group. ${ }^{*} p<0.05$ between control group and 10 days NDV infected group. ns = Non significant.

a Expressed in $\mathrm{U} / \mathrm{mg}$ of protein.

b Nano mol of CDNB conjugate formed/mg of protein/min.

c Milli units/mg of protein.

d $\mathrm{nmol}$ of NADPH oxidized/min/mg of protein.

e $\mathrm{nM} / \mathrm{mg}$ of protein.

f $\mu$ moles of MDA formed/gm wet weight of tissue/h.
Table 3

Effect of Newcastle disease virus infection on the levels of antioxidant and the activities of antioxidant enzymes in the optic lobes of chicken.

\begin{tabular}{lccr}
\hline Parameter & Control & \multicolumn{2}{l}{ NDV infection } \\
\cline { 3 - 4 } & & \multicolumn{1}{l}{4 Days } & \multicolumn{1}{c}{10 Days } \\
\hline Superoxide dismutase $^{\mathrm{a}}$ & $3.01 \pm 0.17$ & $3.14 \pm 0.12^{\mathrm{ns}}$ & $2.51 \pm 0.20^{*}$ \\
Catalase $^{\mathrm{a}}$ & $1.87 \pm 0.04$ & $1.91 \pm 0.03^{\mathrm{ns}}$ & $1.60 \pm 0.09^{*}$ \\
Glutathione-S-transferase $^{\mathrm{b}}$ & $235.47 \pm 12.82$ & $226.23 \pm 8.49^{\mathrm{ns}}$ & $204.08 \pm 7.14^{*}$ \\
Glutathione peroxidase $^{\mathrm{c}}$ & $31.08 \pm 1.23$ & $31.72 \pm 1.51^{\mathrm{ns}}$ & $26.01 \pm 2.96^{*}$ \\
Glutathione reductase $^{\mathrm{d}}$ & $10.65 \pm 0.48$ & $10.88 \pm 0.36^{\mathrm{ns}}$ & $9.90 \pm 0.54^{\mathrm{ns}}$ \\
Reduced glutathione $^{\mathrm{e}}$ & $39.86 \pm 1.06$ & $37.88 \pm 2.39^{\mathrm{ns}}$ & $35.74 \pm 1.86^{\mathrm{ns}}$ \\
Lipid peroxidation $^{\mathrm{f}}$ & $43.28 \pm 1.33$ & $47.39 \pm 1.74$ & $58.94 \pm 2.70^{*}$ \\
\hline
\end{tabular}

Values are expressed as mean \pm S.D of six individual observations. ${ }^{*} p<0.05$ between control group and 10 days NDV infected group. ns = Non significant.

a Expressed in $\mathrm{U} / \mathrm{mg}$ of protein.

b Nano mol of CDNB conjugate formed/mg of protein $/ \mathrm{min}$.

${ }^{c}$ Milli units/mg of protein.

d $\mathrm{nmol}$ of NADPH oxidized/min/mg of protein.

e $\mathrm{nM} / \mathrm{mg}$ of protein.

${ }^{\mathrm{f}} \mu$ moles of MDA formed/gm wet weight of tissue/h.

chicken indicates improper detoxification of hydrogen peroxide radicals and lowered concentration of CAT. A significant decrease in reduced glutathione content was also observed in cerebrum, cerebellum and optic lobes of NDV infected chicken as compared to their respective controls might be due to lower activity of GPx and distribution of transition metals in brain regions. It has been well documented that GPx is an allosteric enzyme and thus presence or lack of the co-substrate, GSH, has significant effect on its activity. The results are in consonance with earlier studies. ${ }^{32}$

GST is well acknowledged enzyme of phase II detoxification mechanism. In the present study the activity of GST was also significantly decreased in cerebrum, cerebellum and optic lobes of NDV infected chicken as compared with control animals. The observed decrease in the activity levels of GST suggests improper scavenging activity of free radicals during viral infection. GST catalyzes the conjugation of reduced glutathione (GSH) with nucleophilic xenobiotics or with cellular components damaged by ROS attack, which leads to their detoxification. The decreased activity of GST in tissues of NDV infected chicken might be due to the decreased bioavailability of GSH. Earlier it has been demonstrated that significant decrease in the activity levels of GST was observed in human epithelial cells infected with Respiratory syncytial virus (RSV). ${ }^{35}$ GR is classically known as recycle enzyme, since GR mediates recycling of reduced glutathione from oxidized

Table 4

Effect of Newcastle disease virus on the levels of antioxidant and the activities of antioxidant enzymes in the brain stem of chicken.

\begin{tabular}{lrrr}
\hline Parameter & \multicolumn{1}{l}{ Control } & \multicolumn{2}{l}{ NDV infection } \\
\cline { 3 - 4 } & & \multicolumn{1}{l}{ 4 Days } & \multicolumn{1}{c}{10 Days } \\
\hline Superoxide dismutase $^{\mathrm{a}}$ & $4.01 \pm 0.14$ & $4.18 \pm 0.23^{\mathrm{ns}}$ & $3.35 \pm 0.13^{\mathrm{ns}}$ \\
Catalase $^{\mathrm{a}}$ & $1.98 \pm 0.04$ & $2.02 \pm 0.04^{\mathrm{ns}}$ & $1.87 \pm 0.14^{\mathrm{ns}}$ \\
Glutathione-S-transferase $^{\mathrm{b}}$ & $203.08 \pm 5.73$ & $202.45 \pm 5.30^{\mathrm{ns}}$ & $198.09 \pm 7.3^{\mathrm{ns}}$ \\
Glutathione peroxidase $^{\mathrm{c}}$ & $33.69 \pm 0.71$ & $33.43 \pm 0.68^{\mathrm{ns}}$ & $31.29 \pm 0.93^{\mathrm{ns}}$ \\
Glutathione reductase $^{\mathrm{d}}$ & $10.46 \pm 0.56$ & $11.07 \pm 0.38^{\mathrm{ns}}$ & $9.95 \pm 1.15^{\mathrm{ns}}$ \\
Reduced glutathione $^{\mathrm{e}}$ & $41.46 \pm 1.85$ & $40.36 \pm 1.55^{\mathrm{ns}}$ & $39.15 \pm 1.08^{\mathrm{ns}}$ \\
Lipid peroxidation $^{\mathrm{f}}$ & $50.61 \pm 1.71$ & $52.68 \pm 2.01$ & $54.3 \pm 1.97^{\mathrm{ns}}$ \\
\hline
\end{tabular}

Values are expressed as mean \pm S.D of six individual observations. $\mathrm{ns}=$ Non significant.

a Expressed in $\mathrm{U} / \mathrm{mg}$ of protein.

b Nano mol of CDNB conjugate formed/mg of protein $/ \mathrm{min}$.

c Milli units/mg of protein.

d $\mathrm{nmol}$ of NADPH oxidized/min/mg of protein.

e $\mathrm{nM} / \mathrm{mg}$ of protein.

f $\mu$ moles of MDA formed/gm wet weight of tissue/h. 
glutathione by using NADPH as a co-factor. However, in the present study the decreased activity of GR in the cerebrum, cerebellum and optic lobes of NDV infected chicken indicates malfunction of this enzyme in recycling GSH which in turn reflects reduced levels of oxidized glutathione (GSSG) due to low GPx activity. In addition, it is believed that GSH/GSSG is the most crucial redox couple that, at least in part, regulates intrinsic antioxidant defense system. Thus, decreased activity levels of GPx, GR, GST and non-enzymatic GSH indicate deteriorated glutathionedetoxification system. Furthermore, slightly perturbations in the antioxidant status in brain stem of NDV infected chicken were also investigated. The region specific distribution of oxidative damage might be due to, variations in cellular as well as regional distribution of antioxidant defenses of brain; therefore it varies respond to metabolic rates associated with generation of ROS during pathophysiology. ${ }^{36}$

Histopathological studies also provided an important evidence for the biochemical analysis (oxidative stress markers). Under microscopic examination stringent distortions in cellular architecture were observed in cerebrum, cerebellum and moderately in optic lobes of NDV infected chicken. The histopathological malformations like, increased glial cell population, perivascular monocyte aggregations, hemorrhage, encephalomalacia and vacuolated cytoplasm along with mononuclear infiltration were observed during NDV (10 dpi) infected chicken. In the light of above results it is clear that, NDV infection evoke, at least in part oxidative stress as evidenced by increased lipid peroxidation (MDA) levels with a significant dwindle in the activities of antioxidant enzymes and reduced glutathione content. On the other hand, histopathological studies were also reinforced the NDV induced oxidative damage in cerebrum, cerebellum and optic lobes of chicken.

\section{Conclusions}

In conclusion, this study provides compelling evidence of NDV induced neuronal toxicity in cerebrum, cerebellum and optic lobes of chicken. Oxidative stress is one of the plausible ways responsible for tissue damage in NDV infection. This oxidative damage can be caused by direct effects of virus on cells and indirect effects by host inflammatory responses and thus, damages the tissue architecture. The current investigation has suggested that, the role of oxidative damage in virus infection of the nervous system may lead to improved therapeutic strategies that will reduce the extent of tissue damage during viral infection without impending the antiviral response of the host system. Further studies are in progress in our laboratory, to understand the molecular mechanisms involved in region specific oxidative stress during NDV infection in chicken.

\section{Author contributions}

Lokanatha Valluru has conceived the idea, involved in designing of the experimental work, provided grants for this investigation and also participated in virus culturing and maintenance. W. Rajendra participated in the designing of study and histopathological studies, drafting of manuscript and co-coordinated the experimental studies. K C Venkata Subbaiah involved in maintenance of experimental animals and treatment, carried out biochemical analysis. All others drafted the manuscript for publication.

\section{Conflicts of interest}

All authors have none to declare.

\section{Acknowledgments}

Dr. Lokanatha Valluru acknowledges the University Grants Commission (F. No. 36-86/2008 (SR) Dt.26.03.2009), New Delhi, India for affording financial assistance. We would like to express our gratitude to Dr. D. Raniprameela, Veterinary Scientist, Dept. of Microbiology, S.V. Veterinary University, Tirupati for providing Newcastle disease virus. We thank Balaji hatcheries for supplying of specific pathogenic free (SPF) experimental animals for this study.

\section{References}

1. Seal BS, King DJ, Sellers HS. The avian response to Newcastle disease virus. Dev Comp Immunol. 2000;24:257-268.

2. Regenmortel Van, Ranquet CM, Bishop DHL. 7th Report of International Committee on Taxonomy of Virus. San Diego, Wien, New York: Academic Press; 2000:1024.

3. Collins MS, Bashiruddin JB, Alexander DJ. Deduced amino acid sequences at the fusion protein cleavage site of Newcastle disease viruses showing variation in antigenicity and pathogenicity. Arch Virol. 1993;128:363-370.

4. Alexander D. Newcastle disease, other avian paramyxoviruses, and pneumovirus infections. In: Saif YM, Barnes HJ, Glisson JR, Fadly AM, McDougald LR, Swayne D, eds. Diseases of Poultry. Ames: Iowa State University Press; 2003: 63-99.

5. Klaunig JF, Xu Y, Isenberg JS, et al. The role of oxidative stress in chemical carcinogenesis. Env Hea Perspect. 1998;106:289-295.

6. Halliwell B, Gutteridge JMC. Free Radicals in Biology and Medicine. London: Clarendon Oxford Press; 1985:320-340.

7. Suseela $M$, Ashok kumar $K$, Anandan $R$, Viswanathan nair PG, Devadasan Changes in tissue defense system in white spot syndrome virus (WSSV) infected Penaeus monodon. Comp Biochem Physiol J Part C. 2007;145:315-320.

8. Hennet T, Peterhans E, Stocker R. Alterations in antioxidant defenses in lung and liver of mice infected with influenza A virus. J Gen Virol. 1992:73:39-46.

9. Benzer F, Yilmaz S. Effects on oxidative stress and antioxidant enzyme activities of experimentally induced Ornithobacterium rhinotracheale infection in Broilers. J Anim Vet Adv. 2009;8:548-553.

10. Akaike T. Role of free radicals in viral pathogenesis and mutation. Rev Med Virol. 2001;11:87-101.

11. Narasa Raju TA, Vijaya Lakshmi A, Anand T, Venkateshwar Rao L, Sharma Gita. Protective effects of quercetin during influenza virus-induced oxidative stress. Asia Pacific J Clin Nutr. 2000;9:314-317.

12. Peterhans E, Grob M, Burge T, Zanoni R. Virus induced formation of reactive oxygen intermediates in phagocytic cells. Free Rad Res Comm. 1987;3: 39-46.

13. Rotruck JT, Pope AL, Ganther HE, Swanson AB, Hafeman DG, Hoekstra WG. Selenium: biochemical roles as a component of glutathione peroxidase. Science. 1973:19:588-590.

14. Keles H, Fidan AF, Cigerci IH, Kucukkurt I, Karadas E, Dundar Y. Increased DNA damage and oxidative stress in chicken with natural Marek's disease. Vet Immunol Immunopathol. 2010;133:51-58.

15. Venkata Subbaiah KC, Raniprameela D, Visveswari G, Rajendra W, Lokanatha V. Perturbations in the antioxidant metabolism during Newcastle disease virus (NDV) infection in chicken: protective role of vitamin E. Naturwissenschaften. 2011:98:1019-1026.

16. Valyi-Nagy T, Dermody TS. Role of oxidative damage in the pathogenesis of viral infections of the nervous system. Histol Histopathol. 2005;20:957-967.

17. Lokanatha V, Rajendra W. Catecholominergic transmission in different brain regions of chick during Newcastle disease virus (NDV) infection. Biochem Mol Biol Int. 1995;36:95-100.

18. Lokanatha $\mathrm{V}$, Rajendra $\mathrm{W}$. The fate of glutamate in different brain regions of the chick during Newcastle disease virus infection. Biochem Mol Biol Int. 1996;38: 215-221.

19. Ritchie BW, Harrison GJ, Harrison RL. Avian Medicine: Principle and Application. Florida: Wingers Publishing, Inc; 1994.

20. Hiroshi O, Ohishi N, Yagi K. Assay of lipid peroxides in animal tissues by thiobarbituric acid reaction. Anal Biochem. 1979;95:351-358.

21. Sedlk J, Lindsay RH. Estimation of total, protein-bound, and nonprotein sulfhydryl groups in tissue with Ellman's reagent. Ann Biochem. 1968;1:192-205.

22. Misra HP, Fridovich I. The role of superoxide anion in the autoxidation of epinephrine and a simple assay for superoxide dismutase. J Biol Chem. 1972;247:3170-3175.

23. Aebi H, Packer L. Catalase in vitro. Methods Enzymol. 1984;105:121-126.

24. Habig WH, Pabst MJ, Jakoby WB. Glutathione $S$-transferase. The first enzymatic step in mercapturic acid formation. J Bio Chem. 1974;249:7130-7139.

25. Dulber RE, Anderson BM. Simultaneous inactivation of the catalytic activities of yeast glutathione reductase by $\mathrm{N}$-alkyl male imides. Biochem Biophy Acta. 1981;659:70-85.

26. Lowry OH, Rosenbrough N, Farr AL, Randall RJ. Protein measurement with the Folin-phenol reagent. J Biol Chem. 1951;193:265-275.

27. Kumar Sandeep, Usha Kant M, Jayantee K, Vinay Kumar K, Khan Mohammad Yahiya. Imbalance in oxidant/antioxidant system in different brain regions of 
rat after the infection of Japanese encephalitis virus. Neuro Chem Inter. 2009;55:648-654.

28. Schwarz KB. Oxidative stress during viral infection. Rev FRBM. 1996;21:641-649.

29. Revillard JP, Vincent CM, Favier AE, Richard MJ, Zittoun M, Kazatchkine MD. Lipid peroxidation in human immunodeficiency virus infection. $J$ Acquir Immune Defic Syndre. 1992;5:637-638.

30. Hassan HM, Fridovich I. Superoxide radical and the oxygen enhancement of the toxicity of paraquat in Escherichia coli. J Biol Chem. 1978;253:81438148.

31. Meleva M, Tancheva L, Bakalova R, Galavov A, Savov V. Effects of vitamin E lipid peroxidation and liver monooxygenase activity in experimental influenza virus infection. Toxicol Let. 2000;114:39-45.
32. Sugino K, Dohi K, Yamada K, Kawassaki T. Changes in the levels of endogenous antioxidants in the liver of mice with experimental endotoxemia and the protective effects of the antioxidants. Surgery. 1988;105:200-206.

33. Comporti M. Glutathione depleting agents and lipid peroxidation. Chem Phys Lipids. 1987;45:143-169.

34. Meister A, Anderson ME. Glutathione. Anal Rev Biochem. 1983;52:711-760.

35. Yashoda M, Tianshung Liu, Castro Shawn M, Garofalo Roberto $P$, Casola Antonella. Respiratory synctial virus induces oxidative stress by modulating antioxidant enzymes. Am J Respr Cell Mol. 2009;41:348-357.

36. Verma RS, Srivastava N. Cholorpyrifos induced alterations in levels of thiobarbituric acid reactive substances and glutathione in different regions of rat brain. Indian J Exp Biol. 2001;2001:174-177. 